\title{
Photonuclear Contributions to SNS Pulse
}

\section{Shapes}

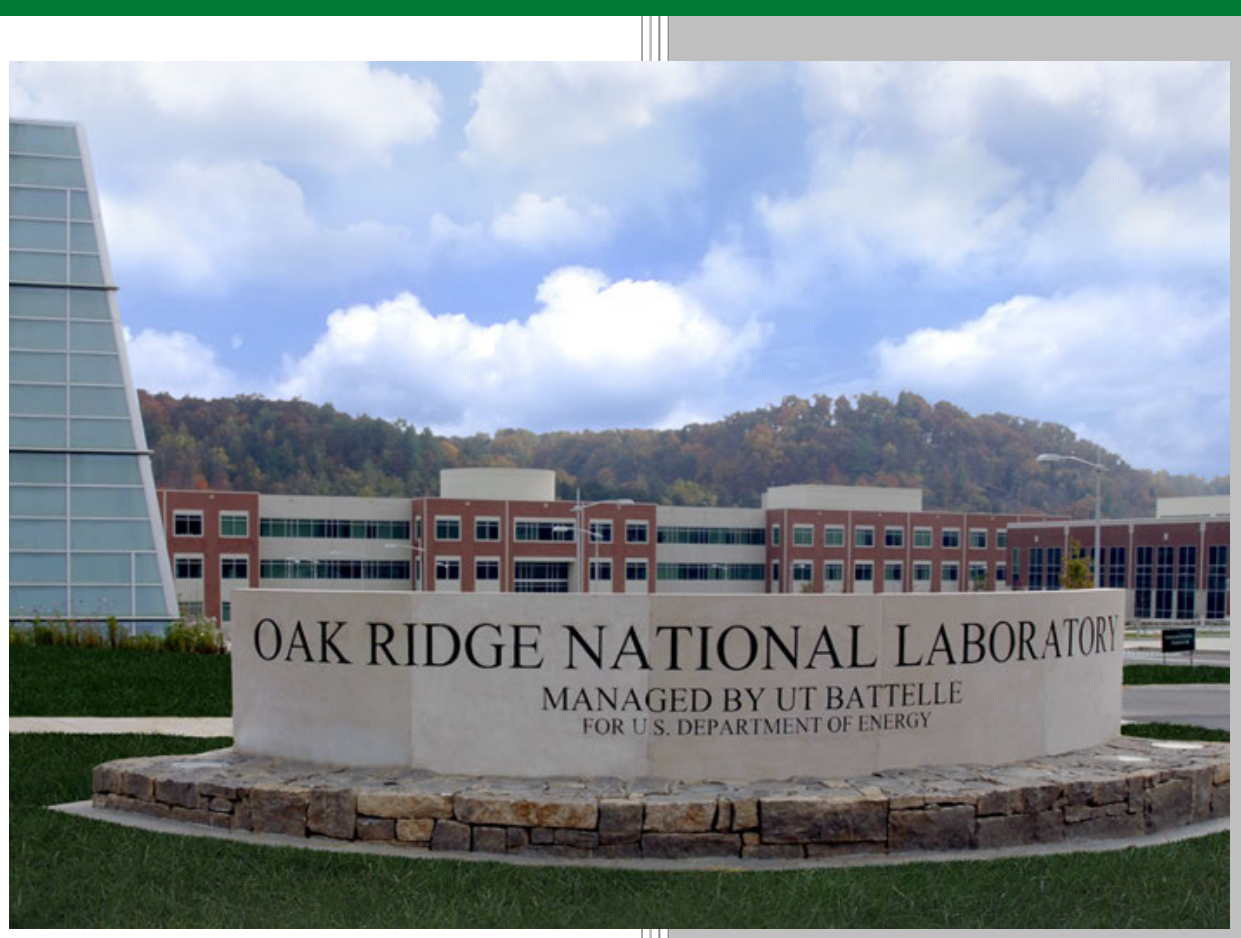

Approved for public release. Distribution is unlimited.

T.C. McClanahan

F.X. Gallmeier

E.B. Iverson

December 2016 


\section{DOCUMENT AVAILABILITY}

Reports produced after January 1, 1996, are generally available free via US Department of Energy (DOE) SciTech Connect.

Website: http://www.osti.gov/scitech/

Reports produced before January 1, 1996, may be purchased by members of the public from the following source:

National Technical Information Service

5285 Port Royal Road

Springfield, VA 22161

Telephone: 703-605-6000 (1-800-553-6847)

TDD: $703-487-4639$

Fax: 703-605-6900

E-mail: info@ntis.fedworld.gov

Website: http://www.ntis.gov/help/ordermethods.aspx

Reports are available to DOE employees, DOE contractors, Energy Technology Data Exchange representatives, and International Nuclear Information System representatives from the following source:

Office of Scientific and Technical Information

PO Box 62

Oak Ridge, TN 37831

Telephone: $865-576-8401$

Fax: 865-576-5728

E-mail: report@osti.gov

Website: http://www.osti.gov/contact.html

This report was prepared as an account of work sponsored by an agency of the United States Government. Neither the United States Government nor any agency thereof, nor any of their employees, makes any warranty, express or implied, or assumes any legal liability or responsibility for the accuracy, completeness, or usefulness of any information, apparatus, product, or process disclosed, or represents that its use would not infringe privately owned rights. Reference herein to any specific commercial product, process, or service by trade name, trademark, manufacturer, or otherwise, does not necessarily constitute or imply its endorsement, recommendation, or favoring by the United States Government or any agency thereof. The views and opinions of authors expressed herein do not necessarily state or reflect those of the United States Government or any agency thereof. 
Instrument and Source Division

\title{
Photonuclear Contributions to SNS Pulse Shapes
}

\author{
T.C. McClanahan \\ F.X. Gallmeier \\ E.B. Iverson
}

Date Published: December 2016

\author{
Prepared by \\ OAK RIDGE NATIONAL LABORATORY \\ Oak Ridge, TN 37831-6283 \\ managed by \\ UT-Battelle, LLC \\ for the \\ US DEPARTMENT OF ENERGY \\ under contract DE-AC05-00OR22725
}




\section{CONTENTS}

LIST OF FIGURES $\ldots \ldots \ldots \ldots \ldots \ldots \ldots \ldots \ldots \ldots \ldots \ldots \ldots \ldots \ldots \ldots$

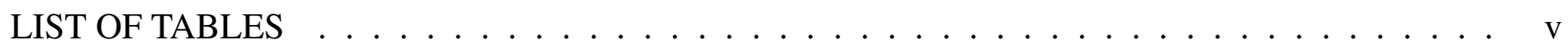

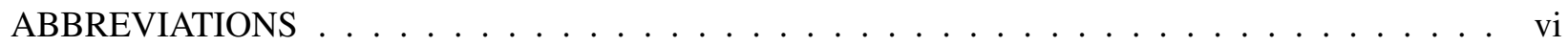

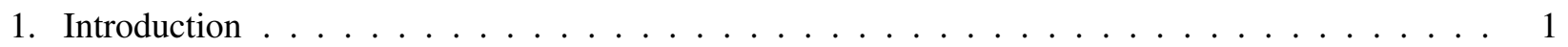

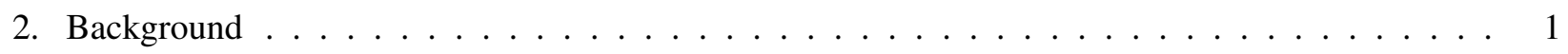

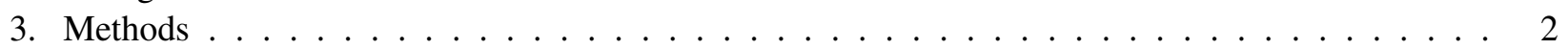

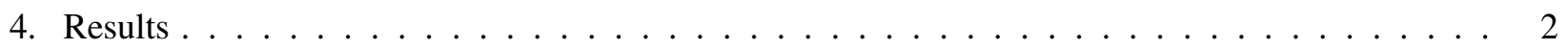

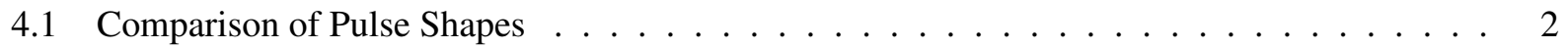

4.2 Timing of Photoneutron Production $\ldots \ldots \ldots \ldots \ldots \ldots$

4.3 Location of Photoneutron Production . . . . . . . . . . . . . . . . . 13

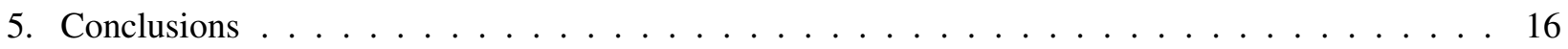

APPENDIX A. Additional Moderator Spectra . . . . . . . . . . . . . . . A-1 


\section{LIST OF FIGURES}

1 Energy integrated (1E-11-1E3 MeV) neutron emission time distribution for the

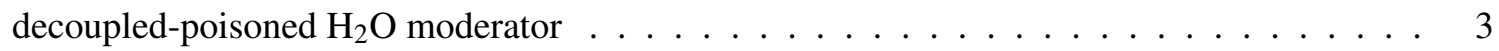

2 Energy integrated neutron emission time distribution for neutron energy $>1 \mathrm{keV}$ for the decoupled-poisoned $\mathrm{H}_{2} \mathrm{O}$ moderator . . . . . . . . . . . . . . . . . . . 4

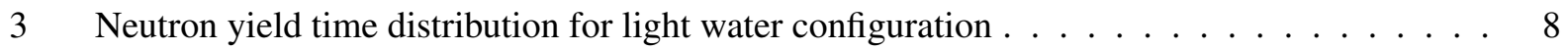

4 Neutron yield time distribution for heavy water configuration . . . . . . . . . . . . 9

5 Cumulative integral of the neutron yield time distribution for the light water configuration . . 11

6 Cumulative integral of the neutron yield time distribution for the heavy water configuration . 12

7 Total photoneutron yield for the light water run $\ldots \ldots \ldots \ldots$

8 Total photoneutron yield for the heavy water run . . . . . . . . . . . . . 15

9 Energy integrated neutron emission time distribution for $>1 \mathrm{keV}$ for the decoupled-poisoned $\mathrm{H}_{2}$ moderator . . . . . . . . . . . . . . . A A-3

10 Energy integrated emission time distribution for $>1 \mathrm{keV} \ldots \ldots \ldots \ldots \ldots$ 


\section{LIST OF TABLES}

$1 \quad \mathrm{H}_{2} \mathrm{O}$ : Energy Integrated Pulse for $1 \mathrm{keV}$ and $\mathrm{up} \ldots \ldots \ldots \ldots$

$2 \quad \mathrm{H}_{2} \mathrm{O}$ PN: Energy Integrated Pulse for $1 \mathrm{keV}$ and up $\ldots \ldots \ldots \ldots$

$3 \quad \mathrm{D}_{2} \mathrm{O}$ : Energy Integrated Pulse for $1 \mathrm{keV}$ and $\mathrm{up} \ldots \ldots \ldots \ldots$

$4 \quad \mathrm{D}_{2} \mathrm{O}$ PN: Energy Integrated Pulse for $1 \mathrm{keV}$ and up $\ldots \ldots \ldots$ 


$\begin{array}{ll} & \\ \text { FTS } & \text { First Target Station } \\ \text { IRP } & \text { Inner Reflector Plug } \\ \text { MCNP } & \text { Monte Carlo N-Particle transport code } \\ \text { ORNL } & \text { Oak Ridge National Laboratory } \\ \text { ORP } & \text { Outer Reflector Plug } \\ \text { SNS } & \text { Spallation Neutron Source } \\ \text { TOF } & \text { Time of Flight }\end{array}$




\section{Introduction}

Short-pulsed sources like the Spallation Neutron Source (SNS) and ISIS produce bursts of neutron pulses at rates of 10-60 Hz, with sub-microsecond proton pulses impacting on high-Z target materials [1]. Moderators are grouped around the target to receive the fast neutrons generated from spallation reactions to moderate them efficiently to thermal and sub-thermal energies and to feed narrow neutron pulses to neutron scattering instruments. The scattering instruments use the neutrons as a probe for material investigations, and make use of time-of-flight (TOF) methods for resolving the neutron energy. The energy resolution of scattering instruments depends on the narrow time-structure of the neutron pulses, while neutrons in the long tail of the emission time distributions can degrade the instrument performance and add undesired background to measurements. The SNS neutronics team is investigating a possible source term impacting the background at short-pulsed spallation sources. The ISIS TS2 project claims to have significantly reduced neutron scattering instrument background levels by the elimination or reduction of iron shielding in the target-moderator-reflector assembly [2]. An alternative hypothesis, also proposed by ISIS, suggests that this apparent reduction arises from moving beamline shielding away from the neutron guide channels, reducing albedo down the beamlines. In both hypotheses, the background neutrons in question are believed to be generated by photonuclear reactions. If the background neutrons are indeed generated via photonuclear channels, then they are generated in a time-dependent fashion, since most of the high-energy photons capable of inducing photonuclear production are gone within a few microseconds following the proton pulse. To evaluate this effect, we have enabled photonuclear reactions in a series of studies for the SNS first target station (FTS) taking advantage of its Monte Carlo model [3, 4]. Using a mixture of ENDF/B VII.0 and TENDL-2014 photonuclear cross sections available and the CEM03 physics model within MCNPX 2.6.0 [5] in the simulation, we are able to estimate the impact of photoneutron production on both overall neutron production and delayed neutron production. We find that a significant number of photon-induced neutrons are produced a few milliseconds after the proton pulse, following prompt gamma emission through the capture of neutrons in the slowing-down and thermalization processes. We name these "slowing-down delayed neutrons" to distinguish them from either "activation-delayed neutrons" or "beta-delayed neutrons." The beta-delayed and activation-delayed neutrons were not part of this study, and will be addressed elsewhere. While these other delayed neutron channels result in the time-independent (constant) production of fast neutrons outside of the prompt pulse, the slowing-down delayed neutrons also affect the shape of the pulses. Although numerically insignificant in most cases, we describe a set of scenarios related to T0-chopper operation in which the slowing-down delayed neutrons may be important.

\section{Background}

Our overall goal is to determine how the photonuclear effects will impact the performance of the moderators at the SNS FTS. Additionally, we will examine how these effects may change on the upcoming replacement of the coolant of the inner reflector plug (IRP), from currently light water to heavy water. With the choice of beryllium as the reflector and the upcoming coolant change from $\mathrm{H}_{2} \mathrm{O}$ to $\mathrm{D}_{2} \mathrm{O}$ in the IRP, the moderators are surrounded with the two materials of lowest photo-nuclear reaction threshold energy. We consider not only the gross effects of additional neutron production, and location of that production, but also the impacts on the detailed emission time distributions from the moderator surfaces, as these time distributions are integral parts of the performance and design of instruments for pulsed neutrons 
sources $[6,7,8,9,10]$.

\section{Methods}

In order to investigate the effects of the slowing-down delayed photoneutrons on the neutron emission time distributions of the FTS moderators, the distributions were calculated with MCNPX v.2.6.0 using a TOF-adjusted point detector tally positioned some distance from the moderator surface with and without the photonuclear reactions enabled [5]. In order to identify the time structure of the photo-neutron production, tallied fluxes were folded with the photon-neutron production cross sections to calculate the production rate in four regions of the FTS and in twelve different materials. Volume averaged flux mesh tallies were used to tally the production locations of the slowing-down delayed photoneutrons.

\section{Results}

Two configurations of the IRP were analyzed to see the how the slowing-down delayed photoneutrons affect the neutron emission time distribution: the current running configuration of the IRP with light water as coolant for the beryllium reflector and other components and a configuration substituting heavy water for light water.

\subsection{Comparison of Pulse Shapes}

We calculated neutron emission for each of the FTS moderators with and without photonuclear effects, in both light and heavy water cooled IRPs. When we compare the time- and energy-integrated neutron intensities, we find that change in total neutron production is apparently significantly smaller than the statistical uncertainty in the Monte Carlo calculation itself. As an example, the photonuclear production for a heavy water cooled IRP increases the total neutron emission from $2.090 \pm 0.001) \times 10^{13}$ to $2.091 \pm 0.002) \times 10^{13} \mathrm{n} / \mathrm{sr} /$ pulse for the upstream side of the top upstream moderator, but decreases it for the other side of the same moderator from $(2.067 \pm 0.001) \times 10^{13}$ to $(2.066 \pm 0.002) \times 10^{13} \mathrm{n} / \mathrm{sr} / \mathrm{pulse}$. Both changes are well within the statistical precision of the results, therefore, we can say that there is no significant difference in the total neutron production due to the photonuclear reaction. When we performed the same calculation looking at the emission time distribution for all neutron energies as shown in Figure 1, we see much the same effect. However, when we integrate the emission time distribution for $\mathrm{E}>1 \mathrm{keV}$, we find that we can clearly distinguish not only photonuclear effects, but also slowing down effects between light and heavy water. Upon reflection, we realize that the emission time distribution shown in Figure 1 (and information for other viewed moderator faces) is energy dependent, and thus we cannot separate out material or photonuclear effects by integrating all energies. By limiting the neutron energy range $1 \mathrm{keV}$ above, as shown in Figure 2, we can clearly distinguish some of the expected photonuclear effects particularly, those which result in neutron emission at times significantly later than the nominal neutron pulse. While we do not directly use these neutrons over $1 \mathrm{keV}$ in energy, they represent the "source term" which is effectively convoluted in time during slowing-down and thermalization and blends in the neutrons we do use. The exact energy chosen here $(1 \mathrm{keV})$ is arbitrarily chosen, because the energy should be below the production energy of the photoneutrons, which in some cases will be around $10 \mathrm{keV}$, but above the energy where we start to use the neutrons (perhaps $10 \mathrm{eV}$ ). The emission time distribution as shown in Figure 2 can be sub-grouped into the emission time distributions for the low energy neutrons as shown in reference 6 , accounting for the photonuclear effects.

In examining Figure 2, we see clearly that adding photonuclear reaction results in an apparent tail of 


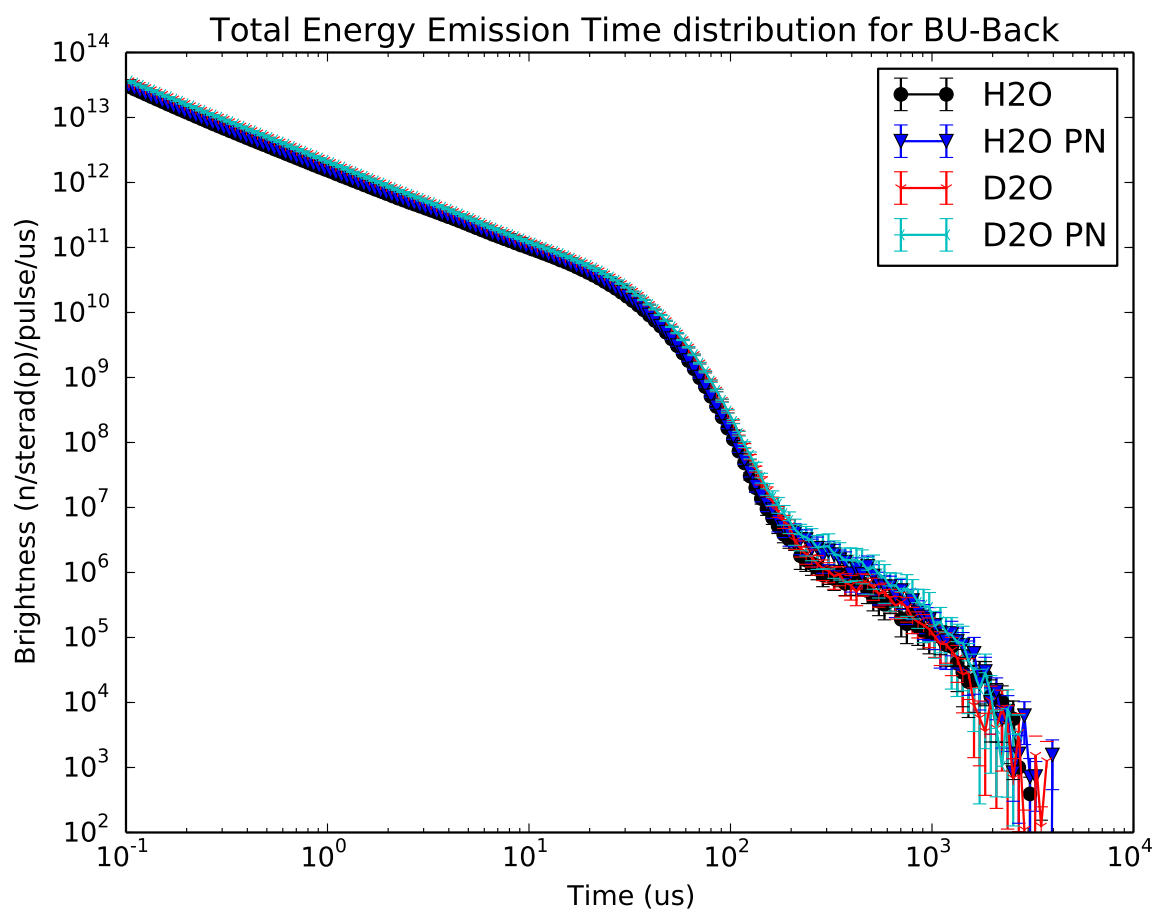

Figure 1. Energy integrated (1E-11-1E3 MeV) neutron emission time distribution for the decoupledpoisoned $\mathrm{H}_{2} \mathrm{O}$ moderator

emission neutrons after around $10 \mu \mathrm{s}$ following the initial proton pulse for neutron energy $>1 \mathrm{keV}$. They appear in a similar fashion in both light and heavy water-cooled systems, and persist for milliseconds, at very low intensities (more than six orders of magnitude below the peak intensity at the beginning of the pulse). By integrating the data shown in Figure 2 over two time regions, from 0 to $10 \mu$ s and from $10 \mu$ s to $10 \mathrm{~ms}$, we can obtain an estimate of this effect that is statistically more robust than the all-energy-integrated results described above. These integrals are shown in Tables 1-4. This separation in time still does not permit us to estimate the magnitude of the prompt photo-induced neutron component, but we can say that it is small. The photoneutrons appearing above $1 \mathrm{keV}$ more than $10 \mu \mathrm{s}$ after the proton pulse appear to be caused by photonuclear reactions of prompt gammas arising from the capture of thermalized neutrons in various materials within the target-moderator-reflector assembly, and thus we describe them as "slowing-down delayed photoneutrons." 


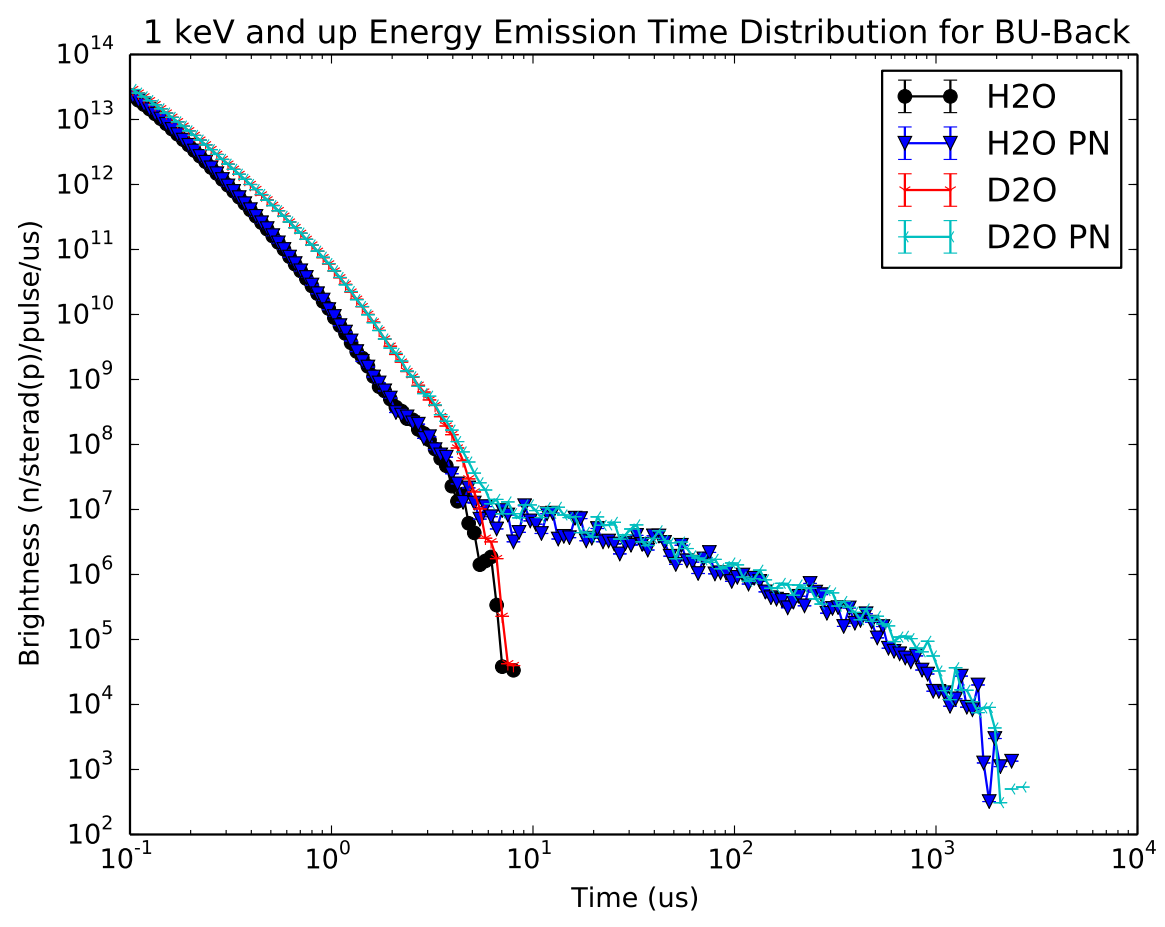

(a) Upstream side

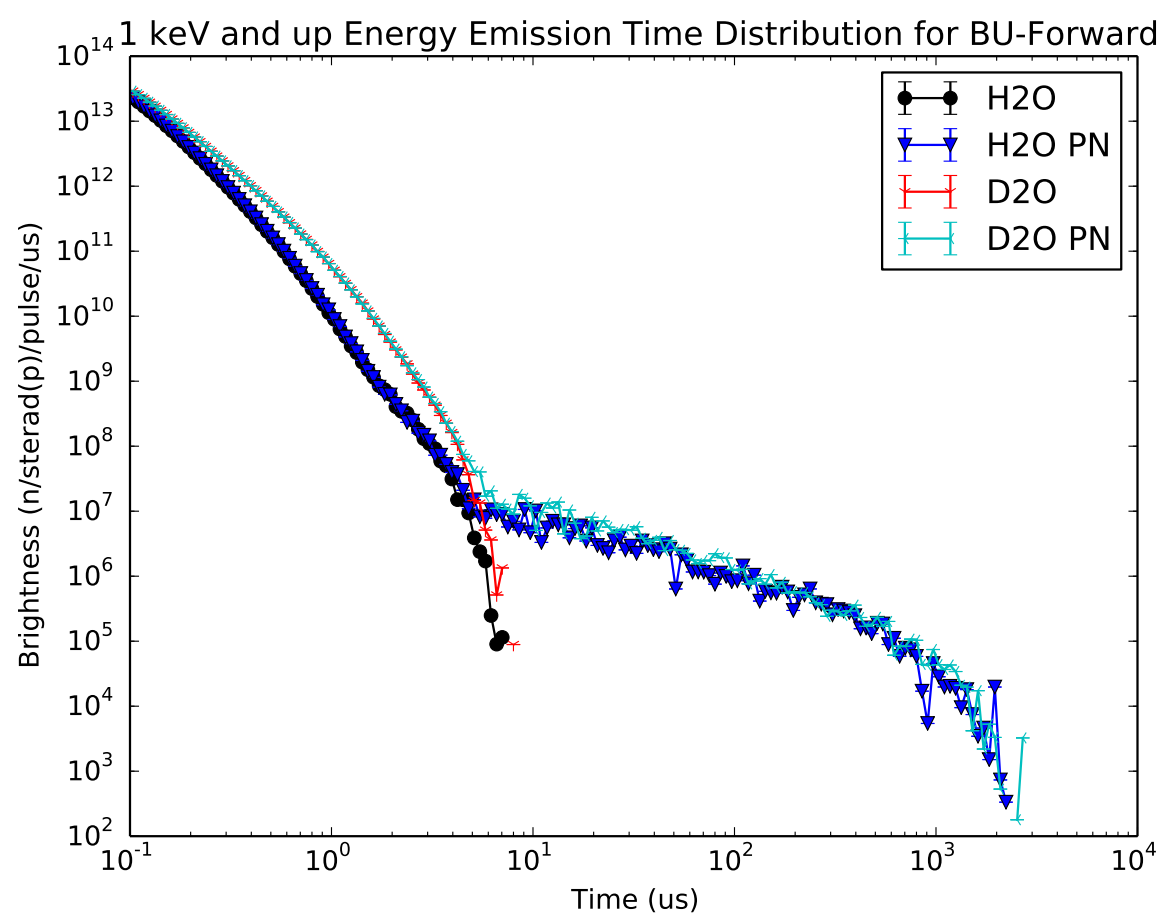

(b) Downstream side

Figure 2. Energy integrated neutron emission time distribution for neutron energy $>1 \mathrm{keV}$ for the decoupled-poisoned $\mathrm{H}_{2} \mathrm{O}$ moderator 
At such low relative magnitude, the slowing-down delayed neutron effect on neutron emission time distributions will not directly affect instruments on the SNS FTS with either light or heavy water IRP coolant. Additionally, this low magnitude (around $10^{-4} \mathrm{n} / \mathrm{sterad} /$ pulse between column A and B) if one looks at the time integrals shown in Table 2) completely explains why such effects were not apparent in the total time- and energy-integral described above. However, the emission of fast neutrons so late after the primary source pulse may be significant as a source of background. Many SNS FTS instruments use T0 choppers - massive blocks of heavy material intended to remove fast neutrons from individual beams by blocking the neutron beamline for some tens of microseconds following the proton pulse, and then opening to permit the passage of (desired) neutrons of energy below a few electron-volts. These late-emitted slowing-down delayed neutrons are not blocked by the T0 chopper. Quantity $\mathrm{C}$ in Tables 1-4 shows a rough estimate of the number of fast neutrons transmitted through $\mathrm{T} 0$ chopper, which can then make background downstream. The ratio $\mathrm{B} / \mathrm{C}$ then shows how much more significant the slowing-down delayed neutrons are than those which are imperfectly attenuated by the T0 chopper. In general, the slowing-down delayed fast neutrons are a few orders of magnitude more intense than the T0-attenuated prompt fast neutrons.

Table 1. $\mathrm{H}_{2} \mathrm{O}$ : Energy Integrated Pulse for $1 \mathrm{keV}$ and up

\begin{tabular}{ccccc}
\hline & $\mathbf{A}^{(a)}$ & $\mathbf{B}^{(b)}$ & $\mathbf{C}^{(c)}$ & $\mathbf{B} / \mathbf{C}$ \\
\hline & $\mathbf{n} / \mathbf{s t e r a d} / \mathbf{p u l s e}$ & $\mathbf{n} / \mathbf{\text { sterad} / \mathbf { p u l s e }}$ & $\mathbf{n} / \mathbf{\text { sterad}} / \mathbf{p u l s e}$ & \\
\hline TU-Back & $(10.090 \pm 0.007) \times 10^{12}$ & $0.0000 \mathrm{E}+00$ & $(10.090 \pm 0.007) \times 10^{5}$ & $0.0000 \mathrm{E}+00$ \\
TU-Forward & $(9.878 \pm 0.007) \times 10^{12}$ & $0.0000 \mathrm{E}+00$ & $(9.878 \pm 0.007) \times 10^{5}$ & $0.0000 \mathrm{E}+00$ \\
BU-Back & $(8.185 \pm 0.006) \times 10^{12}$ & $0.0000 \mathrm{E}+00$ & $(8.185 \pm 0.006) \times 10^{5}$ & $0.0000 \mathrm{E}+00$ \\
BU-Forward & $(8.249 \pm 0.006) \times 10^{12}$ & $0.0000 \mathrm{E}+00$ & $(8.249 \pm 0.006) \times 10^{5}$ & $0.0000 \mathrm{E}+00$ \\
TD & $(4.423 \pm 0.004) \times 10^{12}$ & $0.0000 \mathrm{E}+00$ & $(4.423 \pm 0.004) \times 10^{5}$ & $0.0000 \mathrm{E}+00$ \\
BD & $(4.696 \pm 0.004) \times 10^{12}$ & $0.0000 \mathrm{E}+00$ & $(4.696 \pm 0.004) \times 10^{5}$ & $0.0000 \mathrm{E}+00$ \\
\hline
\end{tabular}

${ }^{(a)} \mathrm{A}=$ Integral of the pulse from 0 to $10 \mu \mathrm{s}$

${ }^{(b)} \mathrm{B}=$ Integral of the pulse from 10 to $1 \mathrm{E} 4 \mu \mathrm{s}$

${ }^{(c)} \mathrm{C}=\mathrm{A} \times 1 E-7$ and approximates the prompt neutrons transmitted through a closed $\mathrm{T} 0$ chopper [11]

Table 2. $\mathrm{H}_{2} \mathrm{O}$ PN: Energy Integrated Pulse for $1 \mathrm{keV}$ and up

\begin{tabular}{ccccc}
\hline & $\mathbf{A}^{(a)}$ & $\mathbf{B}^{(b)}$ & $\mathbf{C}^{(c)}$ & $\mathbf{B} / \mathbf{C}$ \\
\hline & $\mathbf{n} /$ sterad/pulse & n/sterad/pulse & n/sterad/pulse & \\
\hline TU-Back & $(10.079 \pm 0.012) \times 10^{12}$ & $(4.82 \pm 0.60) \times 10^{8}$ & $(10.079 \pm 0.012) \times 10^{5}$ & $(4.78 \pm 0.60) \times 10^{2}$ \\
TU-Forward & $(9.839 \pm 0.012) \times 10^{12}$ & $(4.07 \pm 0.51) \times 10^{8}$ & $(9.839 \pm 0.012) \times 10^{5}$ & $(4.14 \pm 0.53) \times 10^{2}$ \\
BU-Back & $(8.159 \pm 0.011) \times 10^{12}$ & $(3.59 \pm 0.47) \times 10^{8}$ & $(8.159 \pm 0.011) \times 10^{5}$ & $(4.40 \pm 0.58) \times 10^{2}$ \\
BU-Forward & $(8.260 \pm 0.011) \times 10^{12}$ & $(4.33 \pm 0.52) \times 10^{8}$ & $(8.260 \pm 0.011) \times 10^{5}$ & $(5.25 \pm 0.64) \times 10^{2}$ \\
TD & $(4.421 \pm 0.008) \times 10^{12}$ & $(4.86 \pm 0.53) \times 10^{8}$ & $(4.421 \pm 0.008) \times 10^{5}$ & $(11.00 \pm 1.21) \times 10^{2}$ \\
BD & $(4.699 \pm 0.008) \times 10^{12}$ & $(5.89 \pm 0.62) \times 10^{8}$ & $(4.699 \pm 0.008) \times 10^{5}$ & $(12.53 \pm 1.33) \times 10^{2}$ \\
\hline
\end{tabular}

${ }^{(a)} \mathrm{A}=$ Integral of the pulse from 0 to $10 \mu \mathrm{s}$

${ }^{(b)} \mathrm{B}=$ Integral of the pulse from 10 to $1 \mathrm{E} 4 \mu \mathrm{s}$

${ }^{(c)} \mathrm{C}=\mathrm{A} \times 1 E-7$ and approximates the prompt neutrons transmitted through a closed $\mathrm{T} 0$ chopper [11] 
Table 3. $D_{2} \mathrm{O}$ : Energy Integrated Pulse for $1 \mathrm{keV}$ and up

\begin{tabular}{ccccc}
\hline & $\mathbf{A}^{(a)}$ & $\mathbf{B}^{(b)}$ & $\mathbf{C}^{(c)}$ & $\mathbf{B} / \mathbf{C}$ \\
\hline & $\mathbf{n} / \mathbf{s t e r a d} / \mathbf{p u l s e}$ & $\mathbf{n} /$ sterad/pulse & n/sterad/pulse & \\
\hline TU-Back & $(12.019 \pm 0.007) \times 10^{12}$ & $0.0000 \mathrm{E}+00$ & $(12.019 \pm 0.007) \times 10^{5}$ & $0.0000 \mathrm{E}+00$ \\
TU-Forward & $(11.800 \pm 0.007) \times 10^{12}$ & $0.0000 \mathrm{E}+00$ & $(11.800 \pm 0.007) \times 10^{5}$ & $0.0000 \mathrm{E}+00$ \\
BU-Back & $(9.563 \pm 0.007) \times 10^{12}$ & $0.0000 \mathrm{E}+00$ & $(9.563 \pm 0.007) \times 10^{5}$ & $0.0000 \mathrm{E}+00$ \\
BU-Forward & $(9.675 \pm 0.007) \times 10^{12}$ & $0.0000 \mathrm{E}+00$ & $(9.675 \pm 0.007) \times 10^{5}$ & $0.0000 \mathrm{E}+00$ \\
TD & $(5.248 \pm 0.004) \times 10^{12}$ & $0.0000 \mathrm{E}+00$ & $(5.248 \pm 0.004) \times 10^{5}$ & $0.0000 \mathrm{E}+00$ \\
BD & $(5.411 \pm 0.004) \times 10^{12}$ & $0.0000 \mathrm{E}+00$ & $(5.411 \pm 0.004) \times 10^{5}$ & $0.0000 \mathrm{E}+00$ \\
\hline
\end{tabular}

${ }^{(a)} \mathrm{A}=$ Integral of the pulse from 0 to $10 \mu \mathrm{s}$

${ }^{(b)} \mathrm{B}=$ Integral of the pulse from 10 to $1 \mathrm{E} 4 \mu \mathrm{s}$

${ }^{(c)} \mathrm{C}=\mathrm{A} \times 1 E-7$ and approximates the prompt neutrons transmitted through a closed $\mathrm{T} 0$ chopper [11]

Table 4. $D_{2} O$ PN: Energy Integrated Pulse for $1 \mathrm{keV}$ and up

\begin{tabular}{ccccc}
\hline & $\mathbf{A}^{(a)}$ & $\mathbf{B}^{(b)}$ & $\mathbf{C}^{(c)}$ & $\mathbf{B} / \mathbf{C}$ \\
\hline & $\mathbf{n} / \mathbf{s t e r a d} / \mathbf{p u l s e}$ & $\mathbf{n} / \mathbf{\text { sterad} / \text { pulse }}$ & n/sterad/pulse & \\
\hline TU-Back & $(12.018 \pm 0.008) \times 10^{12}$ & $(6.03 \pm 0.42) \times 10^{8}$ & $(12.018 \pm 0.008) \times 10^{5}$ & $(5.02 \pm 0.35) \times 10^{2}$ \\
TU-Forward & $(11.794 \pm 0.008) \times 10^{12}$ & $(5.90 \pm 0.40) \times 10^{8}$ & $(11.794 \pm 0.008) \times 10^{5}$ & $(5.00 \pm 0.34) \times 10^{2}$ \\
BU-Back & $(9.571 \pm 0.008) \times 10^{12}$ & $(5.68 \pm 0.41) \times 10^{8}$ & $(9.571 \pm 0.008) \times 10^{5}$ & $(5.94 \pm 0.43) \times 10^{2}$ \\
BU-Forward & $(9.685 \pm 0.008) \times 10^{12}$ & $(6.08 \pm 0.40) \times 10^{8}$ & $(9.685 \pm 0.008) \times 10^{5}$ & $(6.28 \pm 0.42) \times 10^{2}$ \\
TD & $(5.247 \pm 0.005) \times 10^{12}$ & $(5.06 \pm 0.32) \times 10^{8}$ & $(5.247 \pm 0.005) \times 10^{5}$ & $(9.64 \pm 0.62) \times 10^{2}$ \\
BD & $(5.411 \pm 0.005) \times 10^{12}$ & $(6.15 \pm 0.37) \times 10^{8}$ & $(5.411 \pm 0.005) \times 10^{5}$ & $(11.36 \pm 0.70) \times 10^{2}$ \\
\hline
\end{tabular}

${ }^{(a)} \mathrm{A}=$ Integral of the pulse from 0 to $10 \mu \mathrm{s}$

${ }^{(b)} \mathrm{B}=$ Integral of the pulse from 10 to $1 \mathrm{E} 4 \mu \mathrm{s}$

${ }^{(c)} \mathrm{C}=\mathrm{A} \times 1 E-7$ and approximates the prompt neutrons transmitted through a closed $\mathrm{T} 0$ chopper [11] 


\subsection{Timing of Photoneutron Production}

The reaction rates of the photonuclear reactions were tallied in time in order to evaluate when the majority of the slowing-down delayed photoneutrons are produced and which material is the main contributor to the pulse tail discussed in the previous section. These tallies show when the photoneutrons are produced locally in the systems and that implies that not all of the photoneutrons produced in the systems will be emitted from the moderator surface and contribute to the emission time distribution long-time tail. The reaction rates in Figures $3 \& 4$ show the photoneutron yield for various materials in two regions of the overall target station model: target system, and IRP. Figures $3 \& 4$ show examples of the reaction rate plots for the runs when light and heavy water were used in the IRP, respectively. The dominating contributors to the photoneutron yield for the Target system shown in Figures 3a \& 4a in both cases is the mercury, but these photoneutrons are produced shortly after the incident proton beam and are mostly in the main peak of the neutron pulse. The time structure of the photoneutrons produced in the IRP shown in Figures $3 \mathrm{~b} \& 4 \mathrm{~b}$ have a much different story. The beryllium reflector is the dominant contributor to the neutron yield in both cases but most of the photoneutrons are being born on a much longer time scale than the photoneutrons being born in the target system in mercury. Also, during the heavy water run, the heavy water rises up to challenge the beryllium for the top contributor to the photoneutron yield at those long time scales. However, in neither case of light water or heavy water was the steel a major contributor to the photoneutron production. 


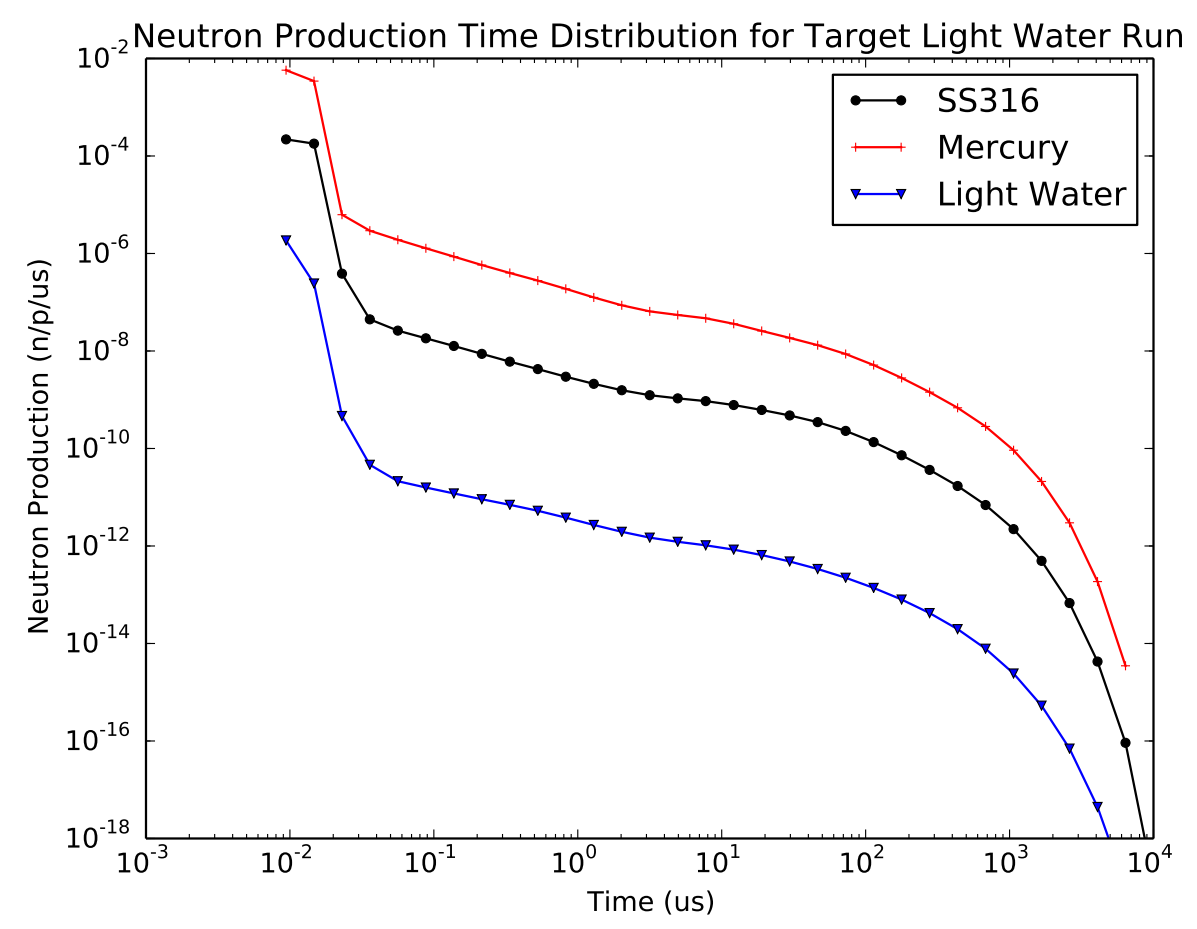

(a) Target System

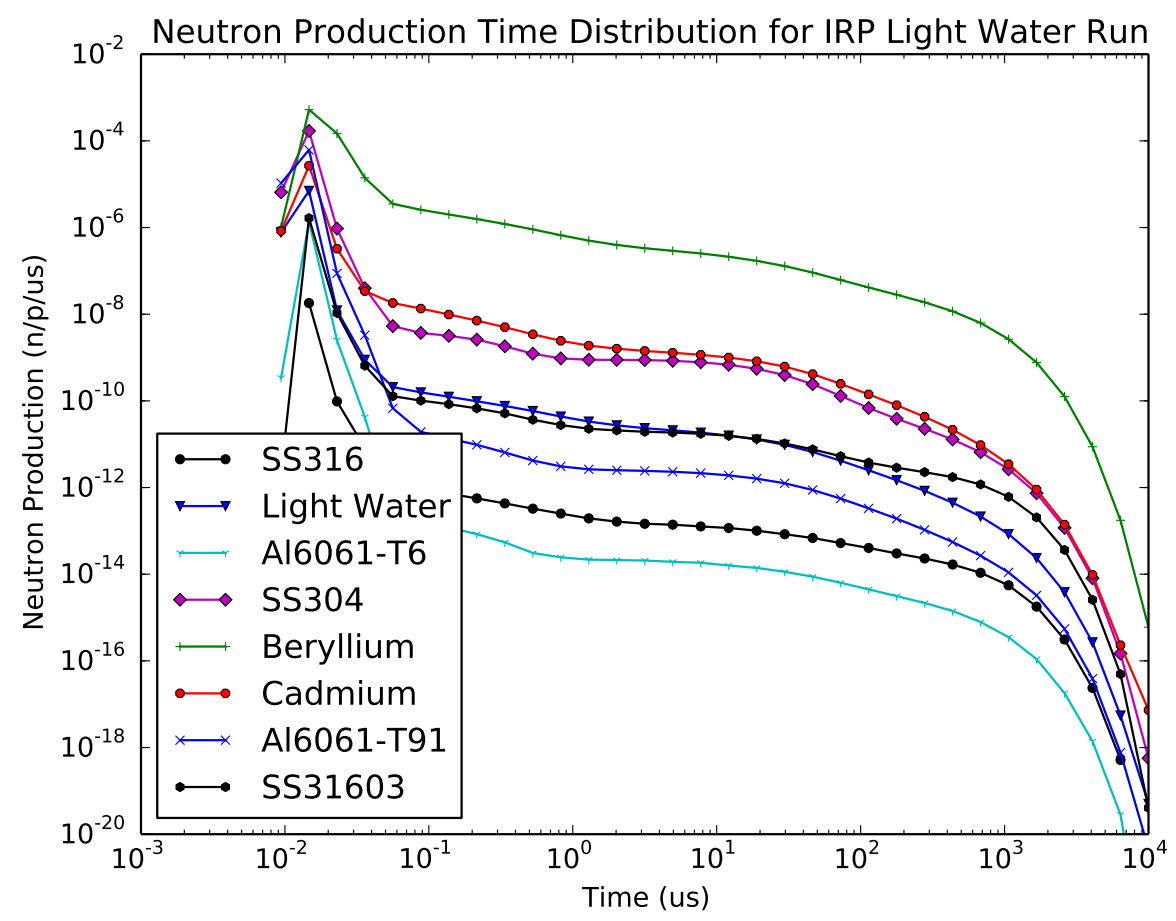

(b) IRP

Figure 3. Neutron yield time distribution for light water configuration 


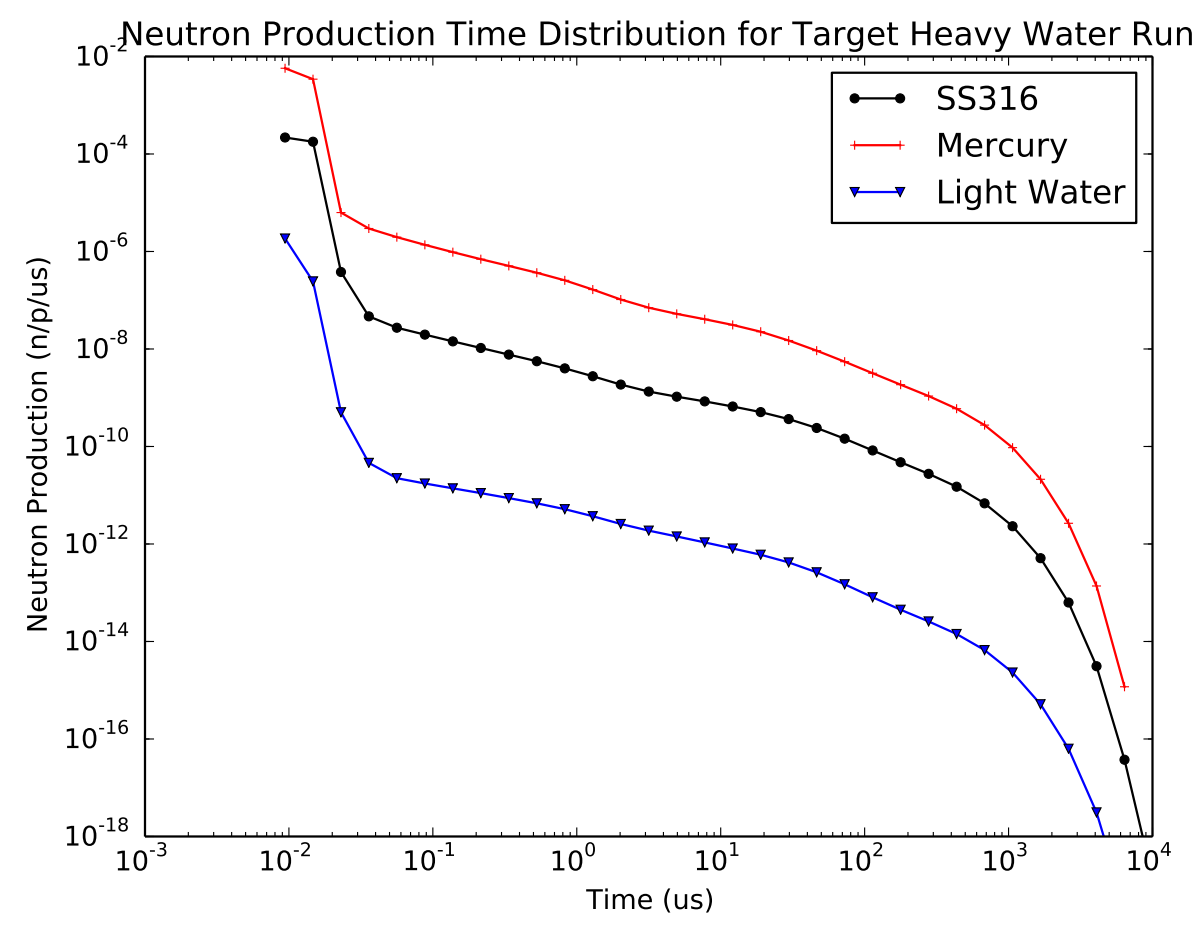

(a) Target System

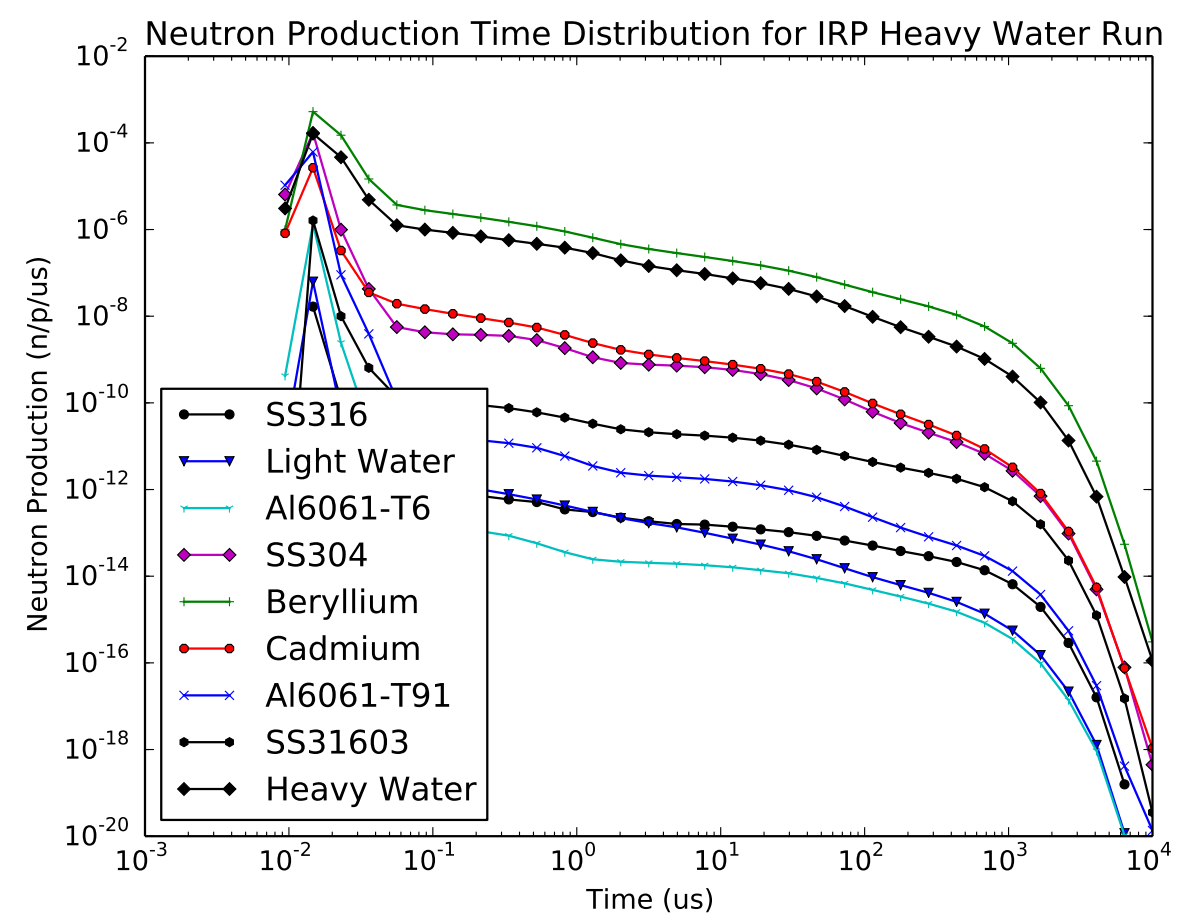

(b) IRP

Figure 4. Neutron yield time distribution for heavy water configuration 
Another method of analyzing the contributions to the photoneutron population is to look at the cumulative integral of the neutron yield rate for the same materials and regions of the target station model. The cumulative integral shows when the bulk of the photoneutron population is born in time. Figures $5 \& 6$ show the cumulative integrals for both the light and heavy water configurations. Figures $5 \mathrm{~b} \& 6 \mathrm{~b}$ show that beryllium has a total neutron yield of almost 1 neutron per 10000 protons and that the bulk of the yield is being born on a later at times between 10 and $1000 \mu$ s. Figure $6 \mathrm{~b}$ shows that heavy water's yield is within a factor of 10 of beryllium at the longer times, and that it follows a similar time structure with regards to when the bulk of the population is born. 


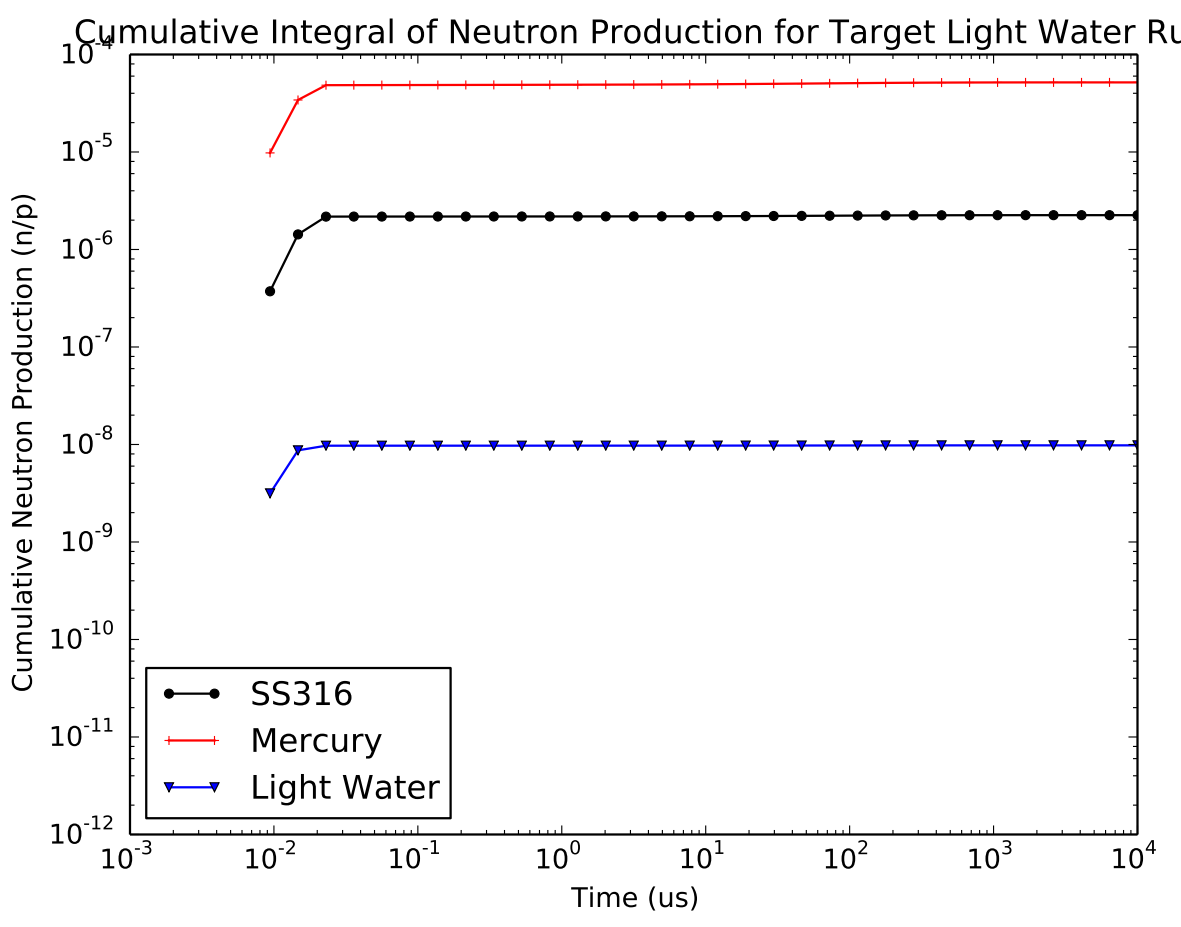

(a) Target System

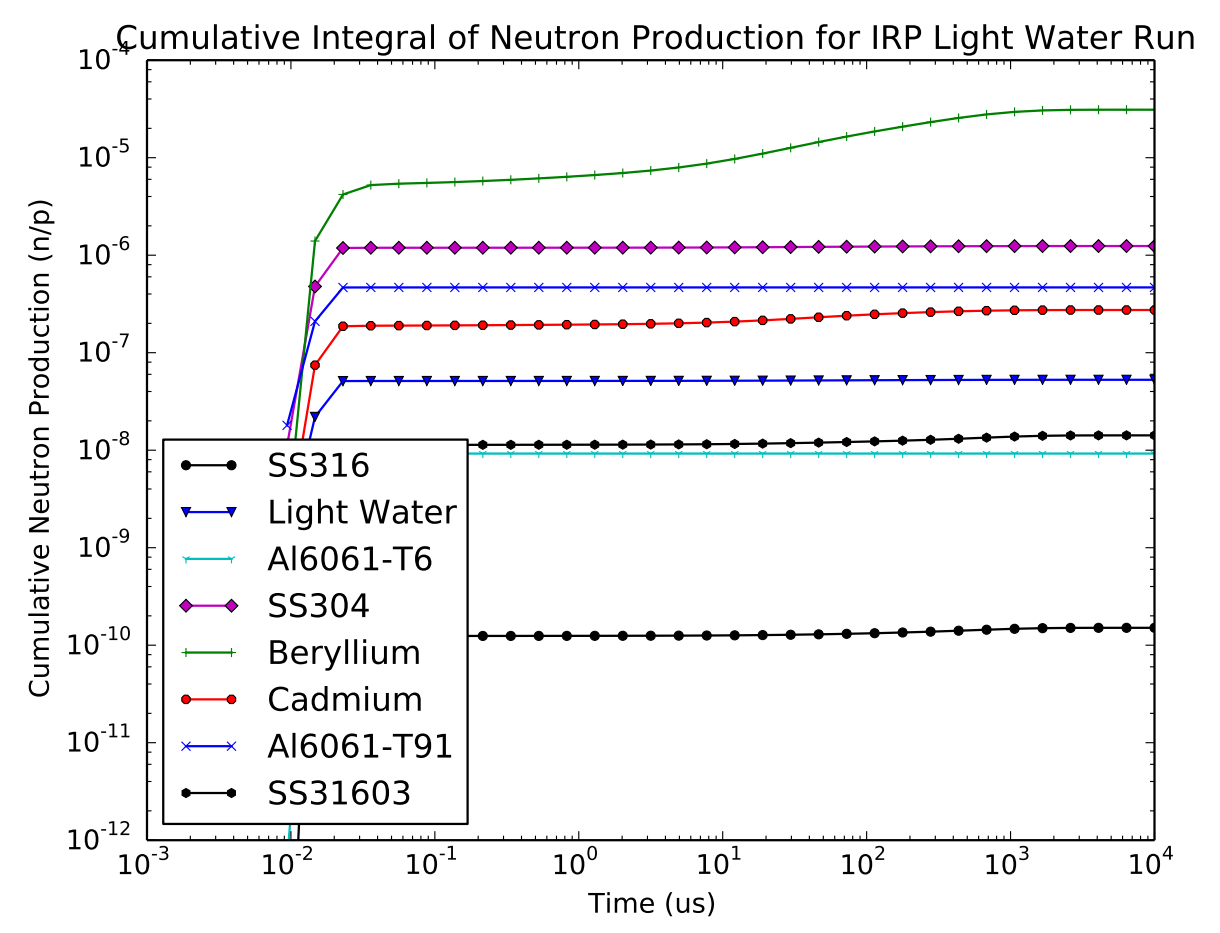

(b) IRP

Figure 5. Cumulative integral of the neutron yield time distribution for the light water configuration 


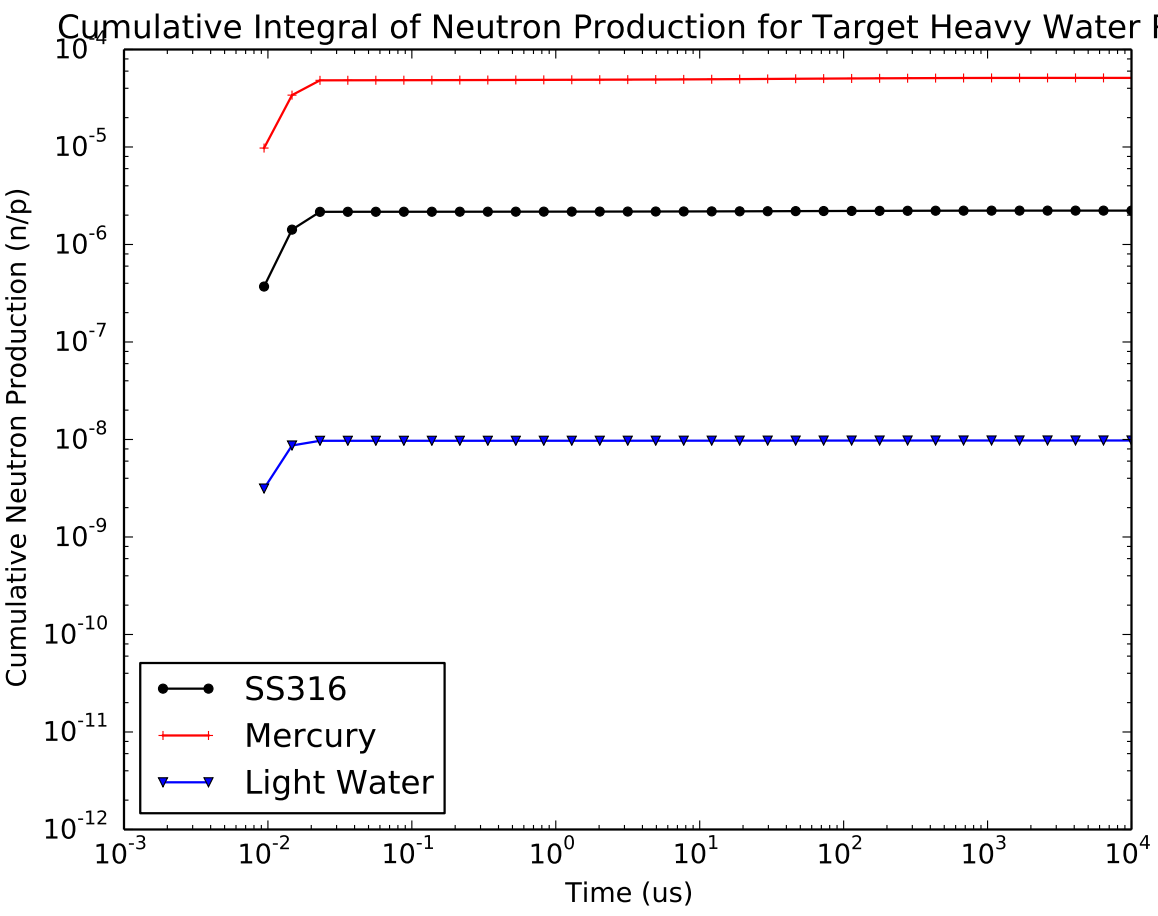

(a) Target System

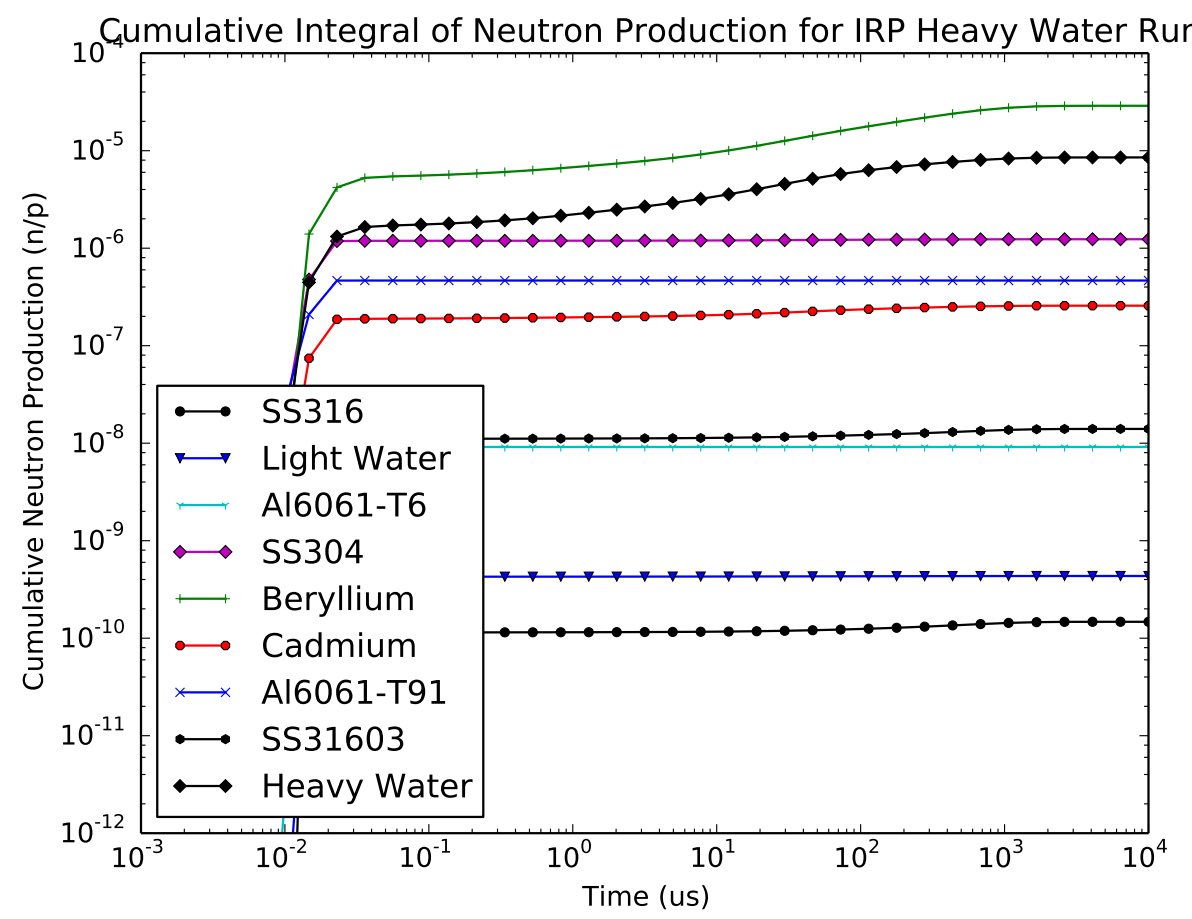

(b) IRP

Figure 6. Cumulative integral of the neutron yield time distribution for the heavy water configuration 


\subsection{Location of Photoneutron Production}

Several mesh tallies were placed in the models to tally the photoneutron production location per material in the overall target station model. Figures $7 \& 8$ show the locations where the photonuclear interactions occur and show the overall photoneutron yield calculated by summing over every material in the target station model. The mercury, beryllium, and heavy water regions are labeled in these figures to show where the major photoneutron yields occur. These figures confirm that the majority of the photoneutron yield is located in the mercury of the target and in the surrounding beryllium reflector. In Figure 8, the heavy water in the outer regions of the ORP contribute a little more to the overall photoneutron yield when compared with the outer regions of the light water run. 


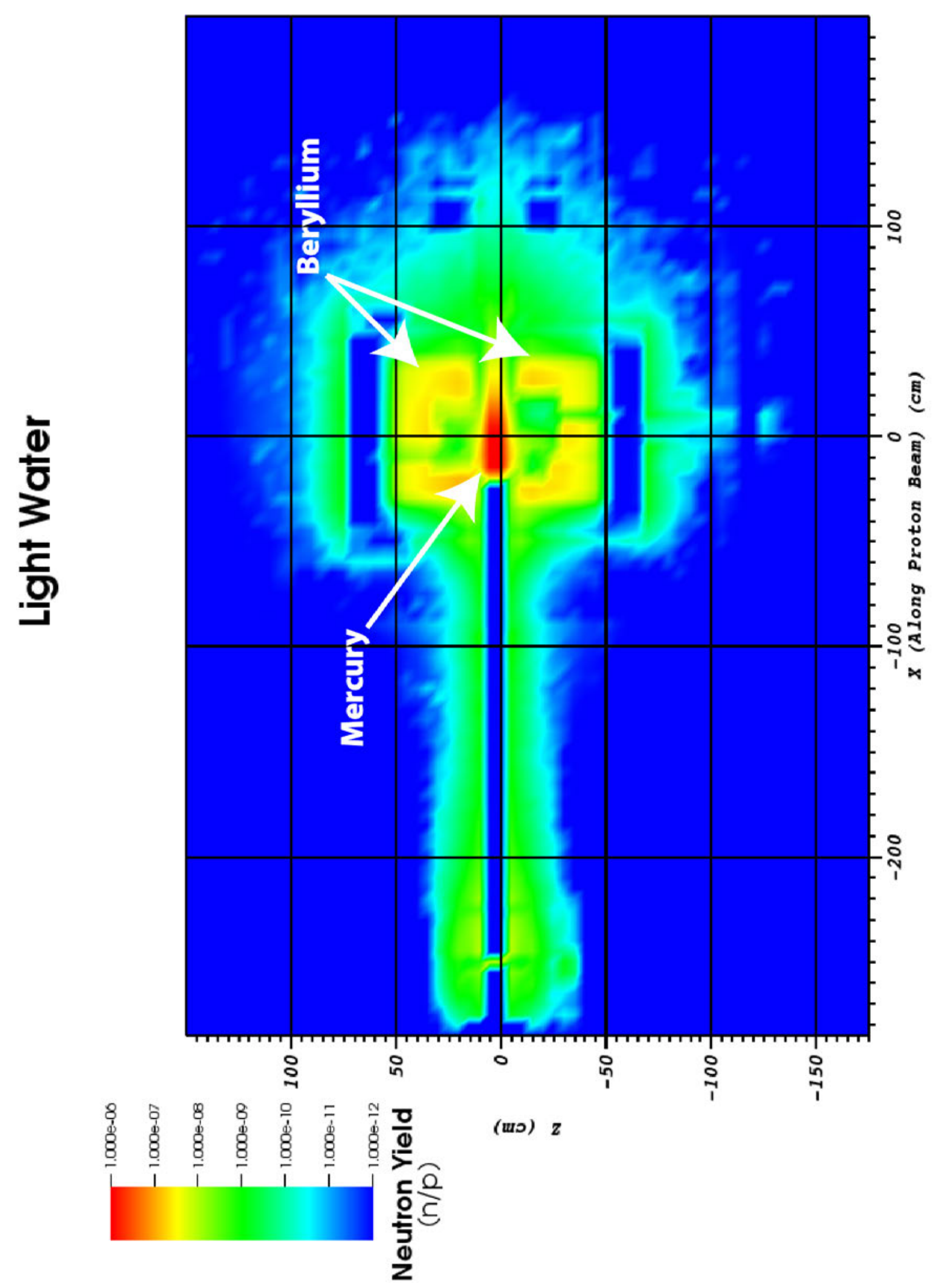

ह0. 


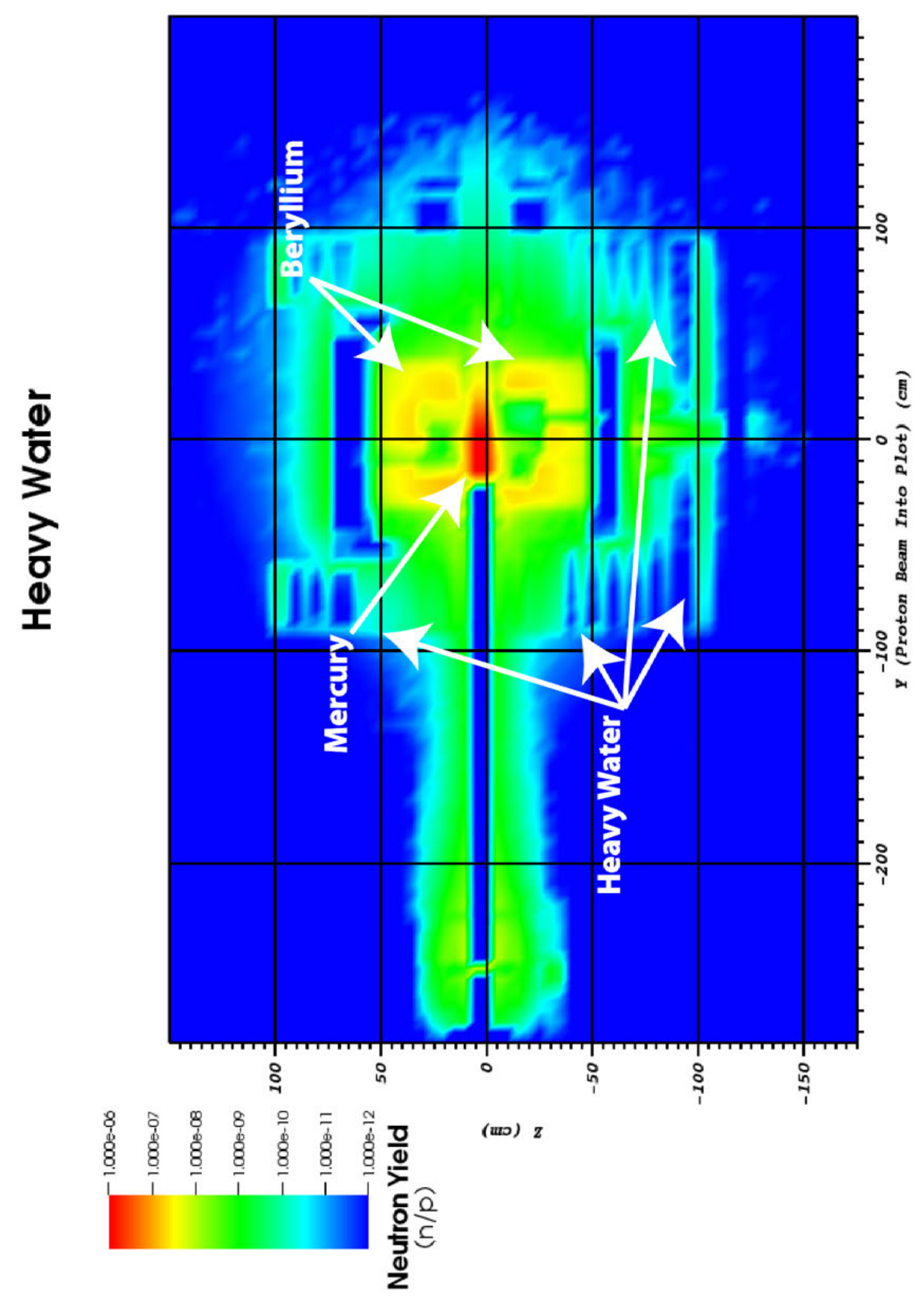

00 


\section{Conclusions}

The effects of the slowing-down delayed neutrons resulted in an increased tail of the neutron emission time distribution for all four of the FTS moderators at long time scales on the order of $10 \mu$ s to $10 \mathrm{~ms}$. At thermal and below thermal energies the moderation and thermalization processes dominate the time structure of the neutron pulses. However, the magnitude of the tail on average four orders of magnitude below the peak of the distribution and not enough to cause concern for the instruments. When considering background effects of the slowing-down delayed photoneutrons, the tail has the potential to be two or three orders of magnitude higher than the $\mathrm{T} 0$ chopper attenuated faster portion of the high energy neutrons. The time tallied reaction rates and the overall mesh tallies confirmed that the beryllium reflector plug is the main contributor to the slowing-down delayed photoneutrons at longer time scales. With regards to the contributions from iron, the production rates of photoneutrons at the FTS from iron do not support the hypothesis that photonuclear effects in iron in the target and reflector contribute to either constant or time-dependent fast neutron background. The mesh tallies over the entire target station model show that the major contributors to the photoneutron population are mercury, beryllium, and heavy water. 


\section{References}

[1] J. M. Carpenter, "Pulsed Spallation Neutron Sources for Slow-Neutron Scattering," Nuclear Instruments $\mathcal{E}$ Methods, vol. 145, no. 1, pp. 91-113, 1977.

[2] P. Bentley and S. Ansell. Private Communication, 2014.

[3] W. Lu, "Moderator Performance of the SNS as-built Configuration," techreport SNS-106100200-TR0199-R00, Oak Ridge National Laboratory, Jan. 2013.

[4] W. Lu, F. Gallmeier, P. Ferguson, E. Iverson, and I. Popova, "Improved moderator performance calculations at SNS," in Tenth International Topical Meeting on Nuclear Applications of Accelerators (AccApp'11), 2011.

[5] D. Pelowitz, "MCNPX User’s Manual,” tech. rep., LANL, apr 2011.

[6] E. B. Iverson, P. D. Ferguson, F. X. Gallmeier, and B. D. Murphy, "The Spallation Neutron Source high power target station moderator performance calculations and studies," Journal of Neutron Research, vol. 11, pp. 83 - 91, 2003.

[7] R. K. Crawford and E. B. Iverson, "Matching source parameters to neutron-scattering-instrument requirements at spallation neutron sources," Transactions of the American Nuclear Society, vol. 79, pp. 392-393, 1998.

[8] F. Gallmeier, E. Iverson, W. Lu, D. Baxter, G. Muhrer, and S. Ansell, "Introducing single-crystal scattering and optical potentials into MCNPX: Predicting neutron emission from a convoluted moderator," Nuclear Instruments and Methods in Physics Research Section A: Accelerators, Spectrometers, Detectors and Associated Equipment, vol. 814, pp. 39-49, 2016.

[9] E. B. Iverson, P. D. Ferguson, F. X. Gallmeier, and I. I. Popova, "Performance characteristics of SNS neutron beams," Transactions of the American Nuclear Society, vol. 89, pp. 673-674, 2003.

[10] B. J. Micklich and E. B. Iverson, "Calculation of pulse shapes for reentrant moderators," in Nuclear Mathematical and Computational Sciences: A Century in Review, A Century Anew, 2003.

[11] E. Iverson. Private Communication, 2016. 


\section{APPENDIX A. Additional Moderator Spectra}


APPENDIX A. Additional Moderator Spectra 


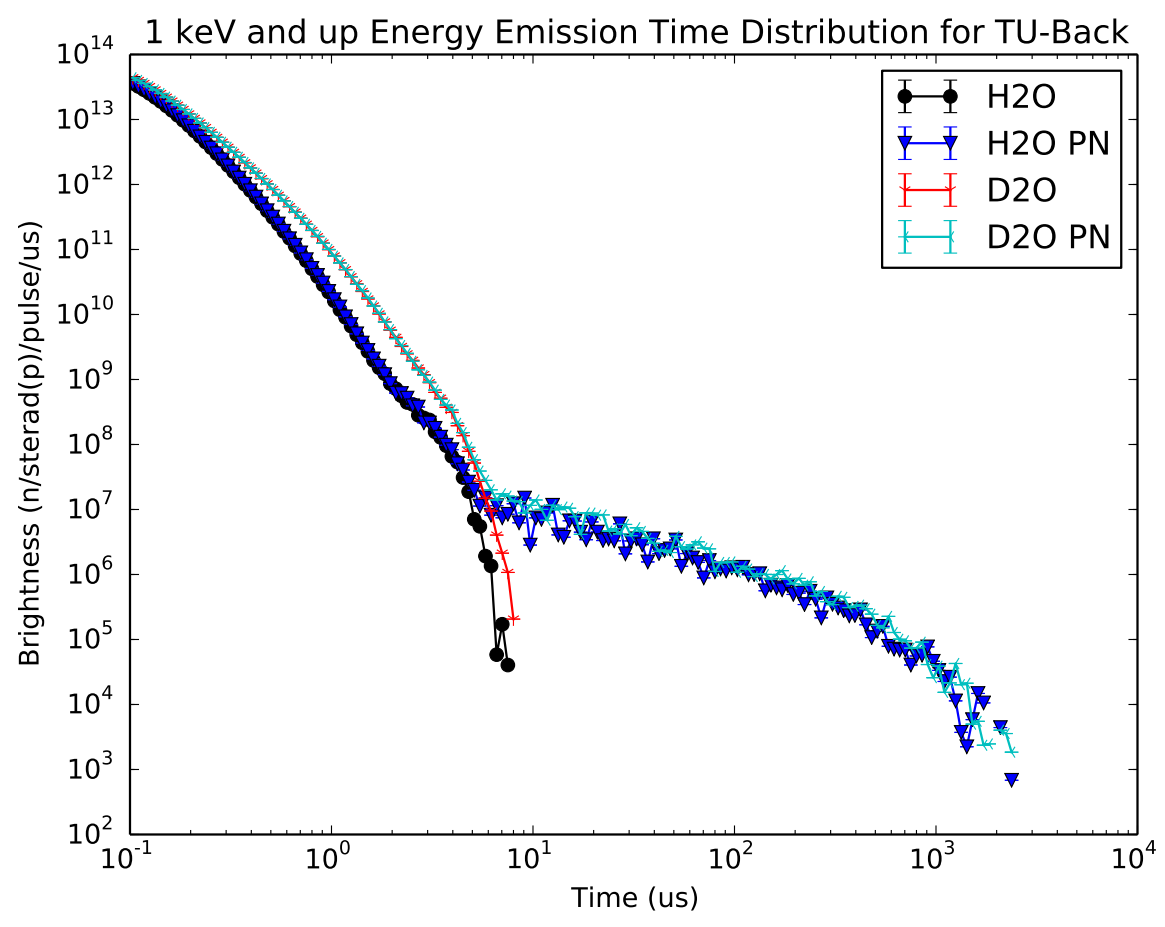

(a) Back side

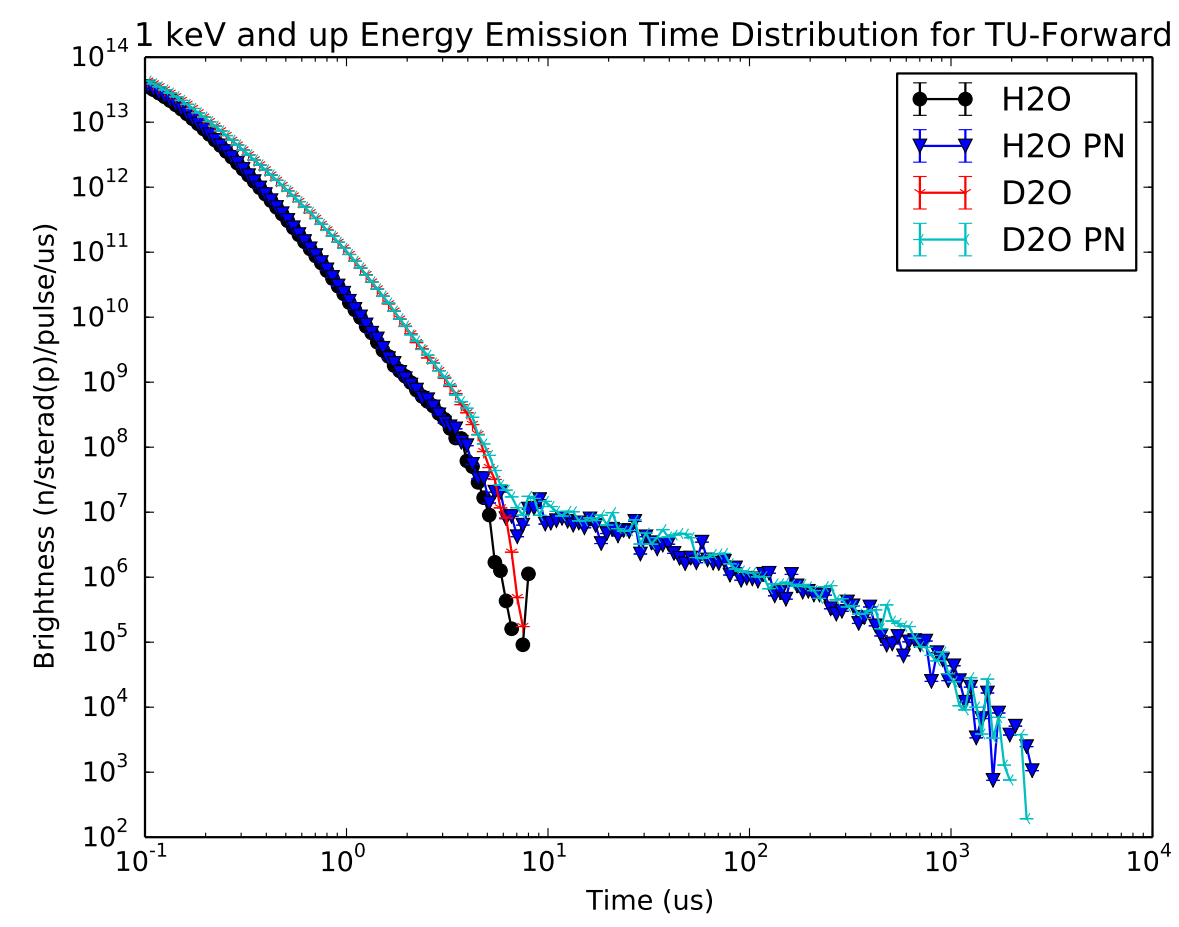

(b) Forward side

Figure 9. Energy integrated neutron emission time distribution for $>1 \mathrm{keV}$ for the decoupled-poisoned $\mathrm{H}_{2}$ moderator 


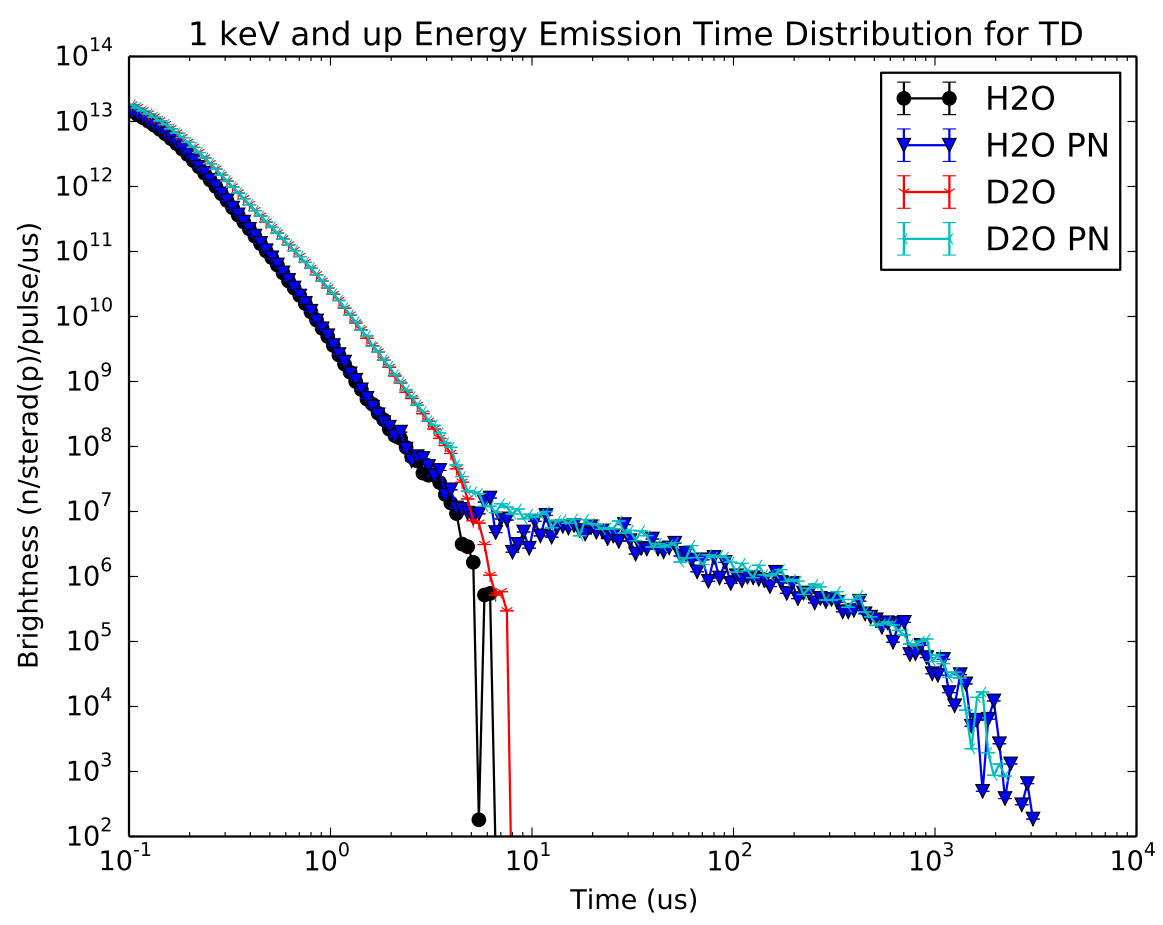

(a) Coupled $\mathrm{H}_{2}$ moderator.

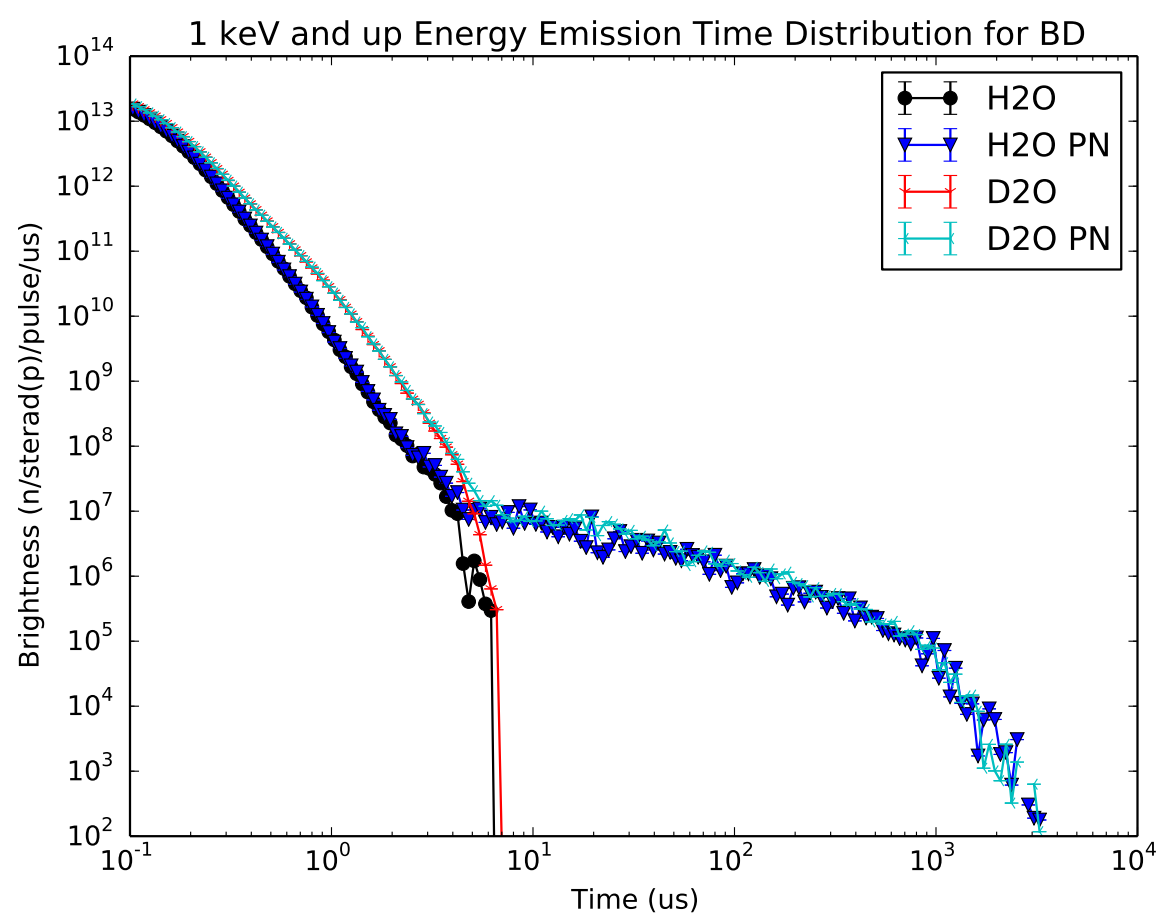

(b) Coupled $\mathrm{H}_{2}$ moderator.

Figure 10. Energy integrated emission time distribution for $>1 \mathrm{keV}$ 